\title{
Seed removal in two coexisting oak species: ecological consequences of seed size, plant cover and seed-drop timing
}

\author{
Ignacio M. Pérez-Ramos, Itziar R. Urbieta, Teodoro Marañón, M. A. Zavala and Richard K. Kobe \\ I. M. Pérez-Ramos (ignacio.perez-ramos@cefe.cnrs.fr), I. R. Urbieta, and T. Marañón, IRNAS, CSIC, P.O. Box 1052, ES-41080 Sevilla, \\ Spain. Present address for IMPR: Centre d'Ecologie Fonctionnelle et Evolutive, CNRS, 1919 Route de Mende, FR-34293 Montpellier 5, France. \\ - M. A. Zavala and present address for IRU: Depto de Ecología, Edificio de Ciencias, Univ. de Alcalá, Alcalá de Henares, ES-28871 Madrid, \\ Spain. - R. K. Kobe, Dept of Forestry, Michigan State Univ., East Lansing, MI 48824-1222, USA.
}

\begin{abstract}
Seed predation and dispersal can critically influence plant community structure and dynamics. Inter-specific differences arising at these early stages play a crucial role on tree recruitment patterns, which in turn could influence forest dynamics and species segregation in heterogeneous environments such as Mediterranean forests. We investigated removal rates from acorns set onto the ground in two coexisting Mediterranean oak species - Quercus canariensis and Q. suber-in southern Spain. We developed maximum likelihood estimators to investigate the main factors controlling probabilities of seed removal and to describe species-specific functional responses. To account for inter-specific differences in seed-drop timing, two experiments were established: a simultaneous exposure of acorns of the two species (synchronous experiments) and a seed exposure following their natural seed-drop phenology (diachronic experiments). A total of 1536 acorns were experimentally distributed along a wide and natural gradient of plant cover, and removal was periodically monitored for three months at two consecutive years (with contrasting differences in seed production and thus seed availability on the ground). The probability of seed removal increased with plant cover (leaf area index, LAI) for the two oak species. Inter-specific differences in acorn removal were higher in open areas and disappeared in closed microhabitats, especially during a non-mast year. Despite later seed-drop, Q. suber acorns were removed faster and at a higher proportion than those of $Q$. canariensis. The higher probability of seed removal for this species could be attributed to its larger seed size compared to Q. canariensis, as inter-specific differences were less pronounced when similar sized acorns were exposed. Inter-specific differences in seed removal, arising from seed size variability and microsite heterogeneity, could be of paramount importance in oak species niche separation, driving stand dynamics and composition along environmental gradients.
\end{abstract}

Differential species requirements during the regeneration phase could contribute to species coexistence in plant communities (Grubb 1977). Differences between species can arise at any stage of the regeneration cycle, including flower fecundity and seed production, seed predation and dispersal, and seedling establishment, mortality and growth (Crawley 1992). In large-seeded species such as temperate oaks, the seed-seedling transition plays a determinant role on tree recruitment. Once seeds reach the ground, a high proportion can be removed and consumed by predators, which usually translates into a major recruitment bottleneck for many forest tree species (Crow 1992, Herrera 1995, Santos and Tellería 1997, Gómez et al. 2003). Moreover, not all removed seeds are necessarily eaten and the small proportion of acorns which are buried and not recovered by animals (especially birds and rodents), acting as secondary dispersers, might be crucial for tree population dynamics (Díaz 1992, Gómez 2003, Purves et al. 2007). Therefore, inter-specific differences in this early phase can be critical for understanding initial tree recruitment patterns, which in turn largely drive forest composition and dynamics (Pacala et al. 1996, Zavala et al. 2000, Zavala and Zea 2004).

Differential preferences by seed predators and dispersers and how these preferences are influenced by environmental conditions could impact seed removal and thereby tree recruitment patterns. First, species-specific seed preferences could respond to differences in intrinsic traits of seeds, such as size, seed-coat thickness, content of defensive compounds or nutritional value (Robbins et al. 1987, Cippolini and Styles, 1991, Ganeshaiah and Shaanker 1991, Brewer 2001, Shimada and Saitoh 2003). Seed size has been attributed as one of the main characters affecting their removal rates. All else being equal, larger seeds should experience greater predation than smaller seeds, since larger food items offer more energetic return for foraging effort (Janzen 1969, Harper 1977, Brewer 2001, Gómez 2004). On the other hand, larger seeds tend to have an increasing probability of being successfully cached and dispersed further away from the parent tree, thus size having a positive effect on dispersal (Gómez et al. 2008, Jansen et al. 2004). Nevertheless, 
preference by larger seeds is not a universal trend (Brewer 2001). Some authors have documented a higher success in the seed-seedling transition for seeds of intermediate (Theimer 2003) or smaller size (Brewer and Webb 2001), whereas others have not found any effect of this trait on seed removal rates (Xiao et al. 2004, Kennedy 2005). In addition, seed preferences are manifested more strongly under higher seed abundance (Brewer 2001, Jansen et al. 2004, Theimer 2004). Therefore, the effect of seed size and how this trait influences the nature of plant-animal interactions appears to be influenced by several factors, including the study system, target species, as well as other external factors such as food availability.

With respect to temporal variability, the predator satiation (Janzen 1971, Silvertown 1980, Kelly and Sork 2002) and animal dispersal hypotheses (Ims 1990) suggest that the strong inter-annual variability in seed production (i.e. mast seeding; Silvertown 1980), commonly found in oak species, is an evolutionary response directed to minimize seed predation pressure, enhance success during seed dispersal and, thereby, favour seedling establishment during mast years (reviewed by Koening et al. 1994, Abrahamson and Layne 2003). These hypotheses could explain why coexisting species that share generalist seed consumers show synchronous masting (Shnurr et al. 2002). Since a species producing seeds out of synchrony may experience a higher probability of seed predation and a lower seedling recruitment (Janzen 1970, Ims 1990, Curran and Leighton 2000), even small inter-specific differences in seed-drop times may have an important effect on the number of seeds that escape predation and that are successfully dispersed. However, the effect of among-species differences in the timing of seed-drop on the process of seed removal has been poorly studied.

Finally, seed removal can also vary spatially because predator and disperser foraging is not random (Clark et al. 1999, Jordano and Schupp 2000). Therefore, there may be a strong link between microhabitat structure and seed removal patterns, particularly in highly-heterogeneous landscapes such as Mediterranean forests (Rey and Alcántara 2000, Kolb et al. 2007).

In addition to the total number of seeds removed (either predated or dispersed), the rate at which seeds are removed can influence successful tree recruitment (Brewer 2001, Jansen et al. 2004). If a seed is cached and not relocated (successful dispersal), a shorter time to removal implies an earlier seedling emergence in the new location, which it is a major determinant of survivorship during the establishment phase (Nicotra et al. 2002, Verdú and Traveset 2005, Castro 2006, Urbieta et al. unpubl.). Conversely, if the seed is eventually consumed, the faster it is removed the lower the chance of germinating and emerging in the site where it was dropped, and thus the lower the probability to be independent from cotyledon reserves (Kennedy et al. 2004).

In this study, we investigate inter-specific variation in seed removal in two oak species - Quercus canariensis (Algerian oak) and Q. suber (cork oak) - in southern Spain (Aljibe mountains). In these mixed forests, acorn availability not only varies inter-annually (seed masting), but also intraannually, due to small phenological differences in seed production and dispersal between the two oak species (Pérez-Ramos 2007). Q. canariensis acorns are dropped in
September-December, whereas Q. suber acorns during October-February. Temporal variation in seed availability, which is generally lower in early autumn, could influence species preferences shown by acorn consumers. Accordingly, Q. suber acorns may be exposed to a lower removal pressure, but counteracting mechanisms, such as production of larger or more palatable seeds, could mitigate the potential effects of later seed-drop. To account for differences in seed-drop phenology, two experiments were established: a simultaneous exposure of acorns of the two species (synchronous experiments), and a seed exposure simulating their natural seed-drop phenology (diachronic experiments) during two consecutive years. Intra and inter-specific differences were evaluated by calibrating maximum likelihood estimators of acorn removal along a wide gradient of plant cover and seed sizes. Specifically, the main objectives were: (1) to examine the effect of seed size and plant cover on species-specific seed removal rates (both in percentage of the total of exposed acorns and taking into account their times to removal), (2) to investigate inter-specific variation in seed removal along gradients of these factors, (3) to evaluate the importance of species differences in seed-drop timing to removal rates, and finally (4) to discuss the ecological implications of these findings for forest stand dynamics and species coexistence.

\section{Methods}

\section{Study area and species}

The study was conducted in La Sauceda forest $(530 \mathrm{~m}$ a.s.l., $\left.36^{\circ} 31^{\prime} 54^{\prime \prime} \mathrm{N}, 5^{\circ} 34^{\prime} 29^{\prime \prime} \mathrm{W}\right)$, located in the mixed oak forests of the Aljibe Mountains, near the Strait of Gibraltar, in southern Spain (see a detailed description of the experimental plot in Quilchano et al. 2008, Pérez-Ramos et al. 2008). The dominant bedrock in the area is OligoMiocenic sandstone, with rugged terrain and a highest peak of $1094 \mathrm{~m}$ a.s.l. The climate is sub-humid Mediterranean, with mild and wet winters, alternating with warm and dry summers. Annual mean temperature is $17^{\circ} \mathrm{C}$, and annual mean rainfall is $1265 \mathrm{~mm}$ (1985-2004 data from La Sauceda meteorological station). Vegetation is dominated by evergreen cork oak $Q$. suber forests, mixed with winter deciduous oaks $Q$. canariensis, which are more abundant near streams (Urbieta et al. 2008). The shrubby understorey is diverse and rich in endemic taxa (Ojeda et al. 2000). Most of the forested area has been protected within Los Alcornocales (meaning cork oak forests) Natural Park, covering about $1700 \mathrm{~km}^{2}$. Large herbivores, such as red deer Cervus elaphus, roe deer Capreolus capreolus and freerange cattle are abundant in this forest.

The fruits (acorns) of oaks usually have a single seed. Q. suber seeds are among the largest from Mediterranean tree species. Its seed production is restricted to the autumn/early winter season (between October and February) and there is strong inter-year variability. During the two sampling years of study (2003/04 and 2004/05 cycles), Q. suber acorn production was low (about $2.3 \mathrm{~g} \mathrm{~m}^{-2}$ year ${ }^{-1}$ ) in the study area (Pérez-Ramos 2007). Q. canariensis acorns are somewhat smaller than those of Q. suber, are dropped earlier (September-December), and exhibit strong inter-year variability in 
seed production; in this case, estimates of acorn production in the study area varied between $344.2 \mathrm{~g} \mathrm{~m}^{-2}$ (2003/04 cycle) and $54.1 \mathrm{~g} \mathrm{~m}^{-2}$ (2004/05 cycle) (Pérez-Ramos 2007). Although most acorns in both species are dispersed only by gravity, a small number potentially could be dispersed by animals (directly from the tree or after they have dropped onto the ground), mainly birds (Bossema 1979, Gómez 2003), rodents (Jensen and Nielsen 1986, Pulido and Díaz 2005, Gómez et al. 2008) and even large insects such as dung beetles (Pérez-Ramos et al. 2007, Verdú et al. 2007).

\section{Experimental design and data collection}

During their period of peak seed production and seed-drop (October-November for Q. canariensis, December-January for Q. suber), we collected acorns under several trees of each oak species to encompass intra-specific variation. We selected healthy, normal-sized acorns and discarded those infected by moth or beetle larvae using a flotation method (Gribko and Jones 1995). Selected acorns were stored on a moist vermiculite bed in plastic trays and kept at $2-4^{\circ} \mathrm{C}$ until their use in the experiment. Acorns were individually marked with a small spot of paint, and were randomly placed on the forest floor in a total of 192 experimental units (minimum distance of $10 \mathrm{~m}$ relative to one another), evenly distributed along the vegetation cover gradient (see below), and labelled with small flags placed at half a meter distance to minimize attraction effects. Acorns were exposed on the surface of the floor, simulating the most common abiotic dispersal process (by gravity). Experimental units spanned a wide and continuous gradient of plant cover, from open habitats (up to $90 \%$ full sun, and leaf area index (LAI) of 0.35), to deeper shade under shrubs and trees (down to 5\% full sun, $4.00 \mathrm{LAI}$ ). Plant cover was estimated by means of hemispherical canopy photographs taken in the centre of each experimental unit in winter (DecemberJanuary), using a horizontally-levelled digital camera with a fish-eye lens of $180^{\circ}$ field of view (see details in Valladares and Guzmán 2006, Quilchano et al. 2008). We used Hemiview Canopy Analysis software (Delta-T Devices Ltd. 1999, ver. 2.1) to analyse the images and to calculate leaf area index, which was selected as the most representative measure of plant cover. Global site factor (GSF, i.e. percentage full sun) and LAI were highly correlated $(r=$ $-0.80, \mathrm{p}<0.001)$.

In order to evaluate the effect of seed-drop timing on seed removal rates, two sets of experiments were carried out: an exposure of seeds simulating the typical phenology of each species (diachronic experiments, DI) and a simultaneous exposure (synchronous experiment, SYN) (Table 1).

\section{Diachronic experiments (DI)}

During the peak seed-drop period of each species, 576 acorns (including both species) were placed during each of the two reproductive cycles, 2003-2004 and 2004-2005 (hereafter DI 03-04 and DI 04-05), across 144 experimental units distributed along a wide and continuous plant cover gradient (see description above). Q. canariensis acorns were first placed in mid October (2003) or early November (2004), while Q. suber acorns were exposed in the field in early December (2003 and 2004) in neighbouring units, so
Table 1. Experimental design scheme for each sampling year.

\begin{tabular}{lll}
\hline $\begin{array}{l}\text { Type of } \\
\text { experiments }\end{array}$ & \multicolumn{1}{c}{ 2003-2004 } & \multicolumn{1}{c}{ 2004-2005 } \\
\cline { 2 - 3 } & \multicolumn{1}{c}{ DI (diachronic) } & \multicolumn{1}{c}{$\begin{array}{c}\text { DI and SYN } \\
\text { (synchronous) }\end{array}$} \\
\hline Censuses & $24 \mathrm{~h}, 7 \mathrm{~d}, 15 \mathrm{~d}, 30 \mathrm{~d}$, & $7 \mathrm{~d}, 30 \mathrm{~d}, 100 \mathrm{~d}$ \\
$\begin{array}{l}\text { Factors measured } \\
\begin{array}{c}\text { Mean seed } \\
\text { production }\end{array}\end{array}$ & LAl $100 \mathrm{~d}$ & $\begin{array}{l}\text { LAl and seed weight } \\
\text { Qsub: } 2.3 \mathrm{~g} \mathrm{~m}^{-2}\end{array}$ \\
$\begin{array}{c}\text { Mean } \pm \text { SD seed } \\
\text { weight }\end{array}$ & Qcan: $344.2 \mathrm{~g} \mathrm{~m}^{-2}$ & $\begin{array}{l}\text { Qsub: } 54.1 \mathrm{~g} \mathrm{~m}^{-2} \\
\text { Qsub: } 5.96 \pm 2.20 \mathrm{~g} \\
(2.31-17.27 \mathrm{~g})\end{array}$ \\
& & $\begin{array}{l}\text { Qsub: } 2.57 \pm 1.03 \mathrm{~g} \\
(0.91-8.29 \mathrm{~g})\end{array}$ \\
\hline
\end{tabular}

that there was no interference between the two species. In each unit, four acorns (without cupule) per species were placed on the ground, in the corners of a $0.5-\mathrm{m}^{2}$ quadrat. Units were periodically visited and acorns individually monitored until there was no longer any evidence of seed removal (approximately after three months). On each visit, the status of the acorn (unaffected, removed, or consumed in situ) was recorded. During the first cycle, censuses were carried out at $24 \mathrm{~h}, 7$ days, 15 days and then monthly (up to 3 months). For the second cycle, three censuses were made, elapsing 7 days, 1 month and 3 months. This approach allowed us to calculate the time elapsing until each experimental acorn was removed. Those acorns remaining unaffected at the end of the experiment were considered as right-censored data. Despite different start dates of acorn placement for the two species, both of them remained exposed to predators and dispersers for the same number of days (up to 100), providing comparable experimental treatments. All experimental acorns, during the second year, were individually weighed to the nearest $0.01 \mathrm{~g}$. Mean $\pm S D$ (standard deviation) acorn fresh weight (g) was: $5.96 \pm 2.20$ for $Q$. suber (range of $2.31-17.27 \mathrm{~g}, \mathrm{n}=576$ ) and $2.57 \pm 1.03$ for $Q$. canariensis (range of $0.91-8.29 \mathrm{~g}$, $\mathrm{n}=576$ ). Acorn fresh weight was used in the analyses as a surrogate of seed size.

\section{Synchronous experiment (SYN)}

Acorns of the two species were placed in the field simultaneously in a synchronous experiment that was carried out in the second reproductive cycle, during late November 2004 (hereafter SYN 04-05), following a similar experimental design. Acorns were experimentally exposed when seed-drop periods of the two oak species overlapped, in order to test whether animals preferred one of the species, excluding the effect of differential seed-fall phenology. Moreover, in this case, acorns of similar mass (i.e. within the same range of seed sizes) were selected for both species in order to remove any possible seed size effect on animal selection. Acorns of both species were mixed and placed at the same time across 48 dispersal units, distributed along the plant cover gradient, with four acorns (two per species) intermixed on each quadrat (total of 192 acorns). Three censuses were made (after 7 days, 1 month and 3 months), recording the status of the acorn (unaffected, removed or consumed in situ). 


\section{Data analyses}

Using maximum likelihood techniques, we fitted linear and non-linear models of acorn removal for each species using two complementary approaches. First, we considered a binomial experiment with each independent trial resulting in just two possible final outcomes, i.e. seed manipulated by animals (removed or consumed in situ) or unaffected after three months of exposure on the forest floor. Since only a small proportion of acorns (below 10\%) were consumed in situ, hereafter we refer to manipulated seeds simply as removed. Second, we conducted failure time analysis (Pyke and Thompson 1986) to evaluate explicitly the time elapsing until a seed is removed. In both approaches, the final (i.e. after three months of exposure) removal probabilities were calculated for each species. However, we will focus on the results obtained by failure time analyses, which captured biologically meaningful responses that were masked by the binomial approach, particularly when removal rates at the end of the experiment were very high (see Appendix 1 for an explicit comparison of the two statistical methods). Failure time analysis considered not only the final 'fate' of each seed (i.e. removed or not) but also the time each seed remained non-removed, thus providing greater temporal resolution in removal rates which could be critical for the regeneration of these species. Since most non-removed acorns germinated during the census intervals, we considered the probability of surviving until germination.

For each oak species, we specified the hazard function as function of LAI and/or seed size (both as continuous variables), fitting several functional responses that covered a wide range of forms: linear, exponential, power and logistic (see Appendix 2 for equations). This modelling approach is suitable to identify strategic axes along which species differentiate (Pacala et al. 1996, Kobe 1999). Specifically, removal models along the plant cover gradient (LAI) were developed for DI 03-04 and SYN 04-05 experiments. For DI 04-05, when individual seed sizes were available, we specified removal models as functions of LAI and seed size.

Models were parameterised with maximum likelihood (Edwards 1992), using a simulating annealing algorithm (Metropolis et al. 1953, Chib and Greenberg 1995). To test for the influence of predictors (seed size and LAI) in seed survival, fitted models were compared to a null model of no factor effect using likelihood ratio tests (LRTs) (Edwards 1992). Fitted models were compared with Akaike's information criteria, specifically $\triangle \mathrm{AIC}$, which is defined for each Model $_{i}$ as: AIC $_{i}-$ AIC minimum (Akaike 1992). The model with the strongest empirical support has the minimum $\mathrm{AIC}$ and thus, $\triangle \mathrm{AIC}=0$. Models with $\triangle \mathrm{AIC}$ between $0-2$ were considered to have equivalent and substantial empirical support, $\triangle \mathrm{AIC}$ between 4-7 indicated less support and models with $\triangle \mathrm{AIC}>10$ were dismissed as they had negligible empirical support (Burnham and Anderson 2002). The effect of oak species on seed removal was analyzed using two complementary approaches. First, we compared a general model that was fit to all the data (model saturated, without distinguishing between the species) versus a model that included species-specific parameters. Second, we estimated 95\% support regions (equivalent to $95 \%$ confidence intervals but used in conjunction with likelihood methods; see details in Hilborn and Mangel 1997) in order to explore inter-specific differences along the plant cover and seed size gradients. When 95\% support regions for the species-specific parameters did not overlap, differences between species were considered to be significantly different. All the models and numerical algorithms were implemented in programs we wrote in C (Borland International Inc. 1996 ver. 5.01).

\section{Results}

Experimentally dispersed Q. canariensis and Q. suber acorns experienced high removal rates in both years of study. In all cases, the probability of seed removal increased exponentially with plant cover (LAI) and seed size for the two oak species (Table 2, 3, 4). Inter-specific differences, however, varied among years and between diachronic and synchronous experiments.

\section{Diachronic experiments (DI)}

In the diachronic experiments (DI 03-04 and DI 04-05), removal rates increased exponentially with LAI for both

Table 2. Maximum likelihood parameter estimates for acorn removal models of each species along the plant cover gradient (LAI), using the failure time approach during DI 03-04 (diachronic experiment). Models are ranked from best to poorest fits.

\begin{tabular}{|c|c|c|c|c|c|c|c|c|c|c|}
\hline DI 03-04 & Factor & Best fit & A & $S$ & Log.Like & $\operatorname{LRT}\left(X^{2}\right)$ & $P$ & DF & $\mathrm{AIC}$ & $\Delta \mathrm{AIC}$ \\
\hline Q. canar & $\begin{array}{l}\text { LAI } \\
\text { LAI } \\
\text { LAI } \\
\text { LAI } \\
\text { Null model }\end{array}$ & $\begin{array}{l}\text { Exponential } \\
\text { Logistic } \\
\text { Linear } \\
\text { Power }\end{array}$ & $\begin{array}{r}0.138 \\
-1.840 \\
0.121 \\
0.262\end{array}$ & $\begin{array}{l}0.529 \\
0.701 \\
0.134 \\
0.583\end{array}$ & $\begin{array}{l}-391.44 \\
-392.99 \\
-393.99 \\
-395.72 \\
-403.88\end{array}$ & $\begin{array}{l}24.9 \\
21.8 \\
19.8 \\
16.3\end{array}$ & $\begin{array}{l}* * * \\
* * * \\
* * * \\
* * *\end{array}$ & $\begin{array}{l}1 \\
1 \\
1 \\
1\end{array}$ & $\begin{array}{l}786.9 \\
790.0 \\
792.0 \\
795.4 \\
809.8\end{array}$ & $\begin{array}{r}0.0 \\
3.1 \\
5.1 \\
8.6 \\
22.9\end{array}$ \\
\hline Q. suber & $\begin{array}{l}\text { LAI } \\
\text { LAI } \\
\text { LAI } \\
\text { LAI } \\
\text { Null model }\end{array}$ & $\begin{array}{l}\text { Exponential } \\
\text { Power } \\
\text { Linear } \\
\text { Logistic }\end{array}$ & $\begin{array}{r}0.139 \\
0.421 \\
-0.044 \\
-1.999\end{array}$ & $\begin{array}{l}0.975 \\
1.313 \\
0.502 \\
1.657\end{array}$ & $\begin{array}{l}-318.89 \\
-327.62 \\
-330.08 \\
-338.52 \\
-382.10\end{array}$ & $\begin{array}{r}126.4 \\
109.0 \\
104.0 \\
87.2\end{array}$ & $\begin{array}{l}* * * \\
* * * \\
* * * \\
* * *\end{array}$ & $\begin{array}{l}1 \\
1 \\
1 \\
1\end{array}$ & $\begin{array}{l}641.8 \\
659.2 \\
664.2 \\
681.0 \\
766.2\end{array}$ & $\begin{array}{r}0.0 \\
17.4 \\
22.4 \\
39.2 \\
124.4\end{array}$ \\
\hline
\end{tabular}

Note: $\mathrm{A}$ and $\mathrm{S}$ are parameter estimates that maximized the likelihood function, and Factor $\mathrm{i}_{\mathrm{i}}$ are the measured predictor variables for each acorn ' $\mathrm{i}$ '. The hazard function can take different forms as expressed in Eq. i-iv (Appendix 2). LogLike. corresponds to the maximum loglikelihood: $\log (\mathrm{L} \theta \mid$ data, model). AIC (Akaike's information criteria) is calculated as: $\mathrm{AIC}=-2 \log (\mathrm{L} \theta \mid$ data, model) $+2 \mathrm{~K}$, being $\mathrm{K}$ the number of parameters in the model. Model fits are evaluated through loglikelihood ratio test $\left(\mathrm{LRT},{ }^{*} \mathrm{p}<0.05,{ }^{* *} \mathrm{p}<0.01, * * * \mathrm{p}<0.001\right)$ and $\Delta \mathrm{AIC}\left(\mathrm{AIC}_{\mathrm{i}}{ }^{-}\right.$ $\mathrm{AIC}_{\mathrm{min}}$ ). Bold font denotes models with equivalent empirical support (i.e. $\Delta \mathrm{AIC}<2$ ). 


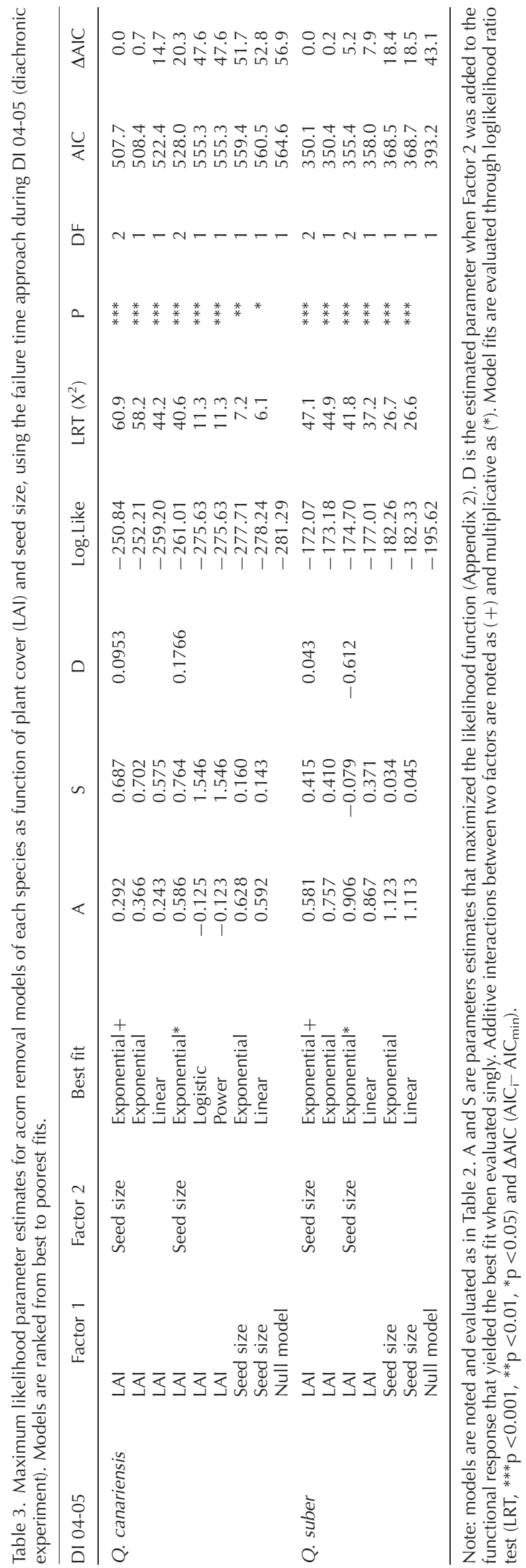

species according to best model fits (i.e. $\Delta \mathrm{AIC}=0)($ Table 2 and 3). During DI 03-04, despite their later placement on the forest floor, $Q$. suber acorns had a higher removal probability than $Q$. canariensis ones as shown by the higher empirical support of models differentiating among the two oak species in comparison with the saturated model $(\triangle \mathrm{AIC}=63.15)$. Inter-specific differences remained along most of the plant cover gradient, with an overlap of $95 \%$ support regions just in the extremes of the LAI gradient (Fig. 1). In open areas (low LAI), the two species had similar removal probabilities $(\approx p=0.4-0.5)$. For intermediate values of plant cover, $Q$. suber acorns always experienced higher removal rates than $Q$. canariensis, whereas in more shaded areas (with denser vegetation) acorns of both species were virtually all removed.

During DI 04-05, seed removal rates were higher than in the previous year for both species (final mean removal of $\approx 93 \%$ ). Again, seed removal rates varied with LAI, which had the strongest empirical support for inclusion in the models (Table 3). Removal increased with LAI for both species, and reached values close to one along a large part of the plant cover gradient. Only in the most open areas (with low LAI), did seeds have some chance to escape from animals, especially those with a smaller size (Fig. 2a), as indicated by the best-supported models $(\triangle \mathrm{AIC}=0)$ for both species (Table 3$)$. In this case, species differences were not supported by the data $(\triangle \mathrm{AIC}=0.03)$. However, for a mean value of seed weight (i.e. $5 \mathrm{~g}$ ), Q. suber acorns had higher removal probability along the plant cover gradient than those of $Q$. canariensis, although inter-specific differences were only noticeable for very low values of LAI (Fig. $2 \mathrm{~b}$ ). In these open areas (i.e. $\mathrm{LAI}=0.5$ ), probability of seed removal also increased with seed size in both oak species, with a more pronounced effect for $Q$. canariensis (Fig. 2c). Q. canariensis acorns (range of $0.9-8.3 \mathrm{~g}$ ) were in general smaller than those of $Q$. suber (2.3-17.3 g), and overall had a lower removal rate. However, in the common interval of acorn size for both species (2.5-8 g), the 95\% support regions overlapped and thus, species did not differ (Fig. 2c).

\section{Synchronous experiment (SYN)}

The importance of seed size on removal probabilities was supported by the synchronous experiment, in which acorns of both species with similar weight were exposed on the ground at the same time. The two oak species experienced very high seed removal rates (approaching 100\%) with overlapping support regions at any level of the plant cover gradient (Fig. 3), thus there was not effect of the species on removal probabilities $(\triangle \mathrm{AIC}=-2.68)$. In this case, removal probabilities also increased with LAI for both species (Table 4).

\section{Discussion}

\section{Factors influencing intra- and inter-specific differences in seed removal}

Our results show divergence in seed removal rates for two co-occurring oak species. Despite their later seed-drop, Q. suber acorns were removed faster and with higher probability in comparison with $Q$. canariensis. These 
Table 4. Maximum likelihood parameter estimates for acorn removal models of each species along the plant cover gradient, during SYN 0405 (Synchronous experiment) using failure time approach. Models are ranked from best to poorest fits and evaluated as in Table 2 and 3 .

\begin{tabular}{|c|c|c|c|c|c|c|c|c|c|c|}
\hline SYN 04-05 & Factor & Best fit & A & S & Log.Like & $\operatorname{LRT}\left(X^{2}\right)$ & $P$ & DF & $\mathrm{AIC}$ & $\Delta \mathrm{AIC}$ \\
\hline Q. can & $\begin{array}{l}\text { LAI } \\
\text { LAI } \\
\text { LAI }\end{array}$ & $\begin{array}{l}\text { Exponential } \\
\text { Linear } \\
\text { Power } \\
\text { Null }\end{array}$ & $\begin{array}{l}0.4934 \\
0.5515 \\
1.0077\end{array}$ & $\begin{array}{l}0.5826 \\
0.4272 \\
0.4503\end{array}$ & $\begin{array}{l}-79.10 \\
-81.09 \\
-82.60 \\
-84.82\end{array}$ & $\begin{array}{r}11.44 \\
7.47 \\
4.45\end{array}$ & $\begin{array}{r}* * * \\
* * \\
*\end{array}$ & $\begin{array}{l}1 \\
1 \\
1\end{array}$ & $\begin{array}{l}162.2 \\
166.2 \\
169.2\end{array}$ & $\begin{array}{l}0.0 \\
4.0 \\
7.0\end{array}$ \\
\hline Q. suber & $\begin{array}{l}\text { LAI } \\
\text { LAI } \\
\text { LAI }\end{array}$ & $\begin{array}{l}\text { Exponential } \\
\text { Linear } \\
\text { Power } \\
\text { Null }\end{array}$ & $\begin{array}{l}0.7432 \\
0.7890 \\
1.1901\end{array}$ & $\begin{array}{l}0.3801 \\
0.3580 \\
0.2898\end{array}$ & $\begin{array}{l}-68.67 \\
-69.39 \\
-70.30 \\
-73.55\end{array}$ & $\begin{array}{l}9.75 \\
8.32 \\
6.49\end{array}$ & $\begin{array}{c}* * \\
* * \\
*\end{array}$ & $\begin{array}{l}1 \\
1 \\
1\end{array}$ & $\begin{array}{l}141.3 \\
142.8 \\
144.6\end{array}$ & $\begin{array}{l}0.0 \\
1.4 \\
3.3\end{array}$ \\
\hline
\end{tabular}

differences, however, varied among years and along plant cover and seed size gradients.

Seed removal was strongly affected by the type of microhabitat where the acorn was placed, highlighting the relevance of environmental variables as mediators of plantanimal interactions (Kolb et al. 2007). Probability of seed removal increased under denser plant cover (i.e. higher LAI values) for both oak species. This positive relation is usually attributed to the action of small rodents, which show a higher activity in more closed microhabitats, where they find more protection against their predators (Kikuzawa 1988, Herrera 1995, Hulme and Hunt 1999, Gómez et al. 2003, Pons and Pausas 2007b).

Seed removal patterns of both species varied between the two sampled years, likely arising from variable acorn production between reproductive cycles, which led to variable food resources (acorns) for seed consumers on the forest floor. During the first cycle 2003/04, the estimated seed production (especially of Q. canariensis) was very high. In the diachronic experiment (DI 03-04), Q. canariensis acorns (that were sown earlier) were removed less by animals than those of $Q$. suber, along most of the vegetation cover gradient. The high availability of resources (acorns) may have resulted in seed-predator satiation (Janzen 1971, Crawley and Long 1995, Wolf 1996) and species-specific seed preferences may have been more perceptible (Jansen et al. 2004). In contrast, during the second cycle (2004/05), estimated seed production of both species was very low, and removal probabilities of experimental seeds approached $100 \%$. Under food scarcity, animals are usually less selective because they need a greater percentage of seeds to build up enough reserves for surviving the next season (Jansen et al. 2002). In this case, inter-specific differences were only perceptible in open areas, where rodents probably selected more attractive food ( $Q$. suber acorns) to compensate for the risk.

In the range of plant cover where inter-specific differences were significant, $Q$. suber acorns were always removed faster and at a higher proportion than $Q$. canariensis acorns, independent of seed availability on the forest floor. In fact, in another forest site within the study area, Pérez-Ramos and Marañón (2008) also found a higher preference for acorns of this species, even when the estimated seed production of $Q$. suber was higher than $Q$. canariensis. These results do not support the initial hypothesis proposing a lower removal risk for $Q$. suber acorns due to their later seed-drop phenology and later availability for animals (assumed as being satiated with the earlier available Q. canariensis acorns), but instead suggest the likely influence of other factors related to specific characteristics of acorns. Differences in seed removal between the two oak species here seem to be mostly a consequence of seed size variation. Overall, Q. suber acorns were bigger than those of Q. canariensis and this was probably the main cause of being removed faster by animals. Indeed, both in synchronous and diachronic experiments, inter-specific differences in removal rates were not significant when a similar seed size range was explored. Therefore, although seed removal rate for Q. suber likely was reduced due to its delayed seed-drop phenology, the greater size of acorns makes them more attractive for animals than $Q$. canariensis ones. At the intraspecific level, the probability of seed removal also increased with seed weight in both species, consistent with previous studies (Gómez 2004, Jansen et al. 2004, Gómez et al. 2008). The influence of seed size on inter-specific differences has been reported in other forest systems (Forget et al. 1998, Xiao et al. 2006), but contrasts with some studies where this trait did not exert any significant effect (Kennedy 2005, Xiao et al. 2004) or animal selection was influenced by other species-specific traits and not by seed size (Hulme and Borelli 1999, Pons and Pausas 2007b, 2007c). In any case, differences in seed quality between $Q$. suber and Q. canariensis acorns, independently of size, should also be investigated. Although a previous seed chemical analysis showed that nutritional content was similar in acorns of both oak species (Pérez-Ramos 2007), inter-specific differences in defensive compounds (e.g. tannins) have not been

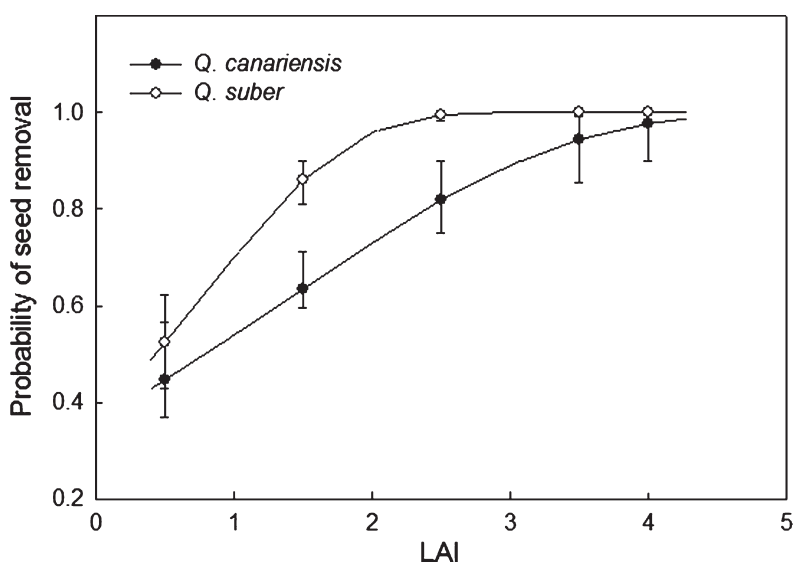

Figure 1. Models resulting in the best fit for acorn removal along a plant cover gradient (expressed by leaf area index, LAI), with 95\% support regions, during DI 03-04 experiment. Final seed removal probabilities (after three months of exposure on the forest floor) increase differently with LAI for both oak species. 

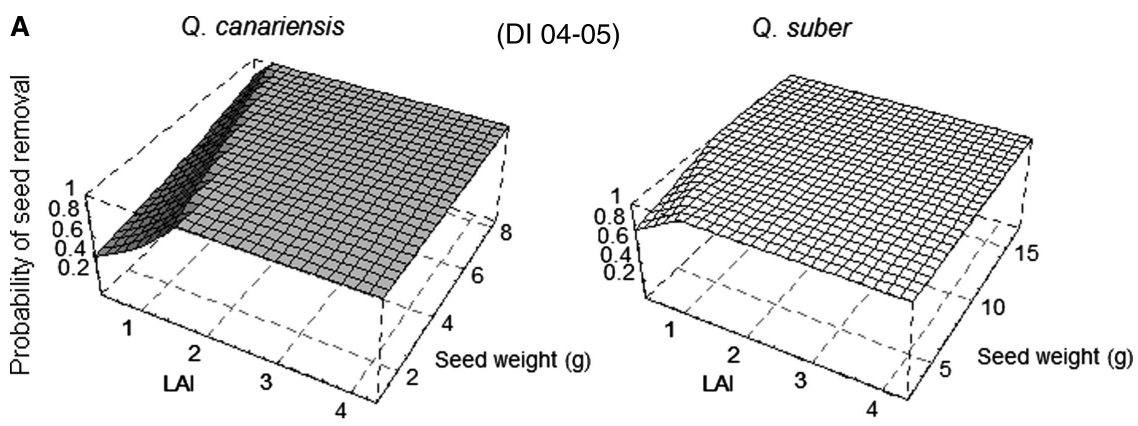

B

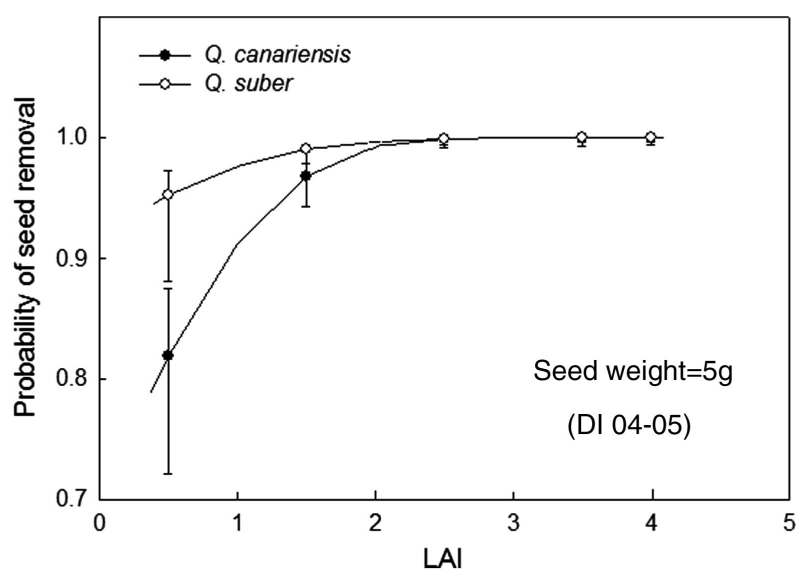

C

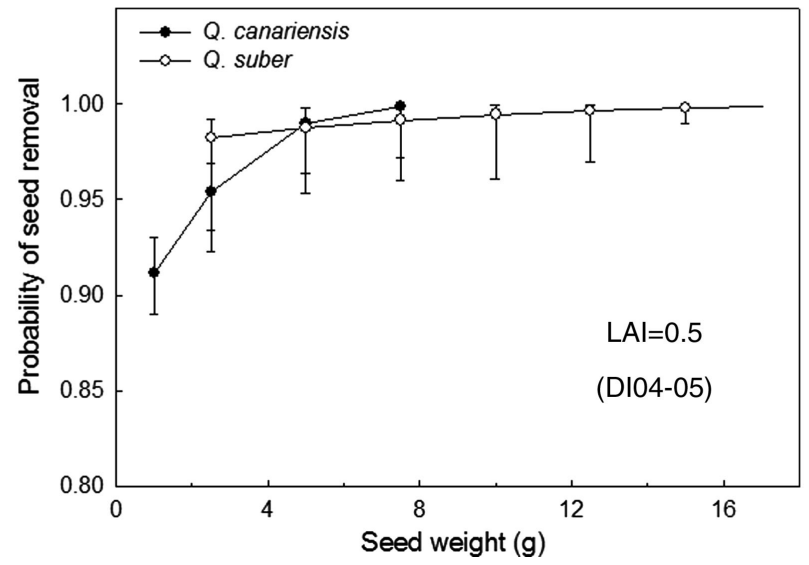

Figure 2. (a) Models resulting in the best fit for acorn removal as function of plant cover (leaf area index, LAI) and seed weight (g), with 95\% support regions, during DI 04-05 experiment. Final seed removal probabilities increase with LAI and seed weight for both oak species. Notice different scales in the axes. (b) Inter-specific differences in removal probabilities along the plant cover gradient for an average seed weight of $5 \mathrm{~g}$. (c) Inter-specific differences in removal probabilities as function of seed weight for a given point of the plant cover gradient $(\mathrm{LAI}=0.5)$.

analysed and also could play an important role (Shimada and Saitoh 2003).

\section{Implications of seed removal for forest stand dynamics}

Seed removal of the two oak species $-Q$. canariensis and Q. suber-was very high during the two years of study. In just three months, a large proportion of experimental acorns placed onto the ground were removed by animals; thus, seedseedling transition could be an important bottleneck in regeneration of the studied oaks, as has been documented for other species (Crow 1992, Herrera 1995, Santos and Tellería 1997, Gómez et al. 2003). A high proportion of acorns removed by the different seed harvesters (mostly rodents) are relocated and eaten later (Bossema 1979, Kikuzawa 1988, Iida 1996, Kollmann and Schill 1996). However, it is likely that a small fraction escapes consumption, in which case mice act as secondary dispersers (Jensen and Nielsen 1986, Pulido and Díaz 2005, Gómez et al. 2008). A similar interaction was documented for dung beetles, Thorectes lusitanicus, in the same forest site; interestingly they bury but do not always eat Q. canariensis and Q. suber acorns (Pérez-Ramos et al. 2007). Thus, the small proportion of buried, surviving seeds discarded or forgotten by these scatterhoarder animals at 


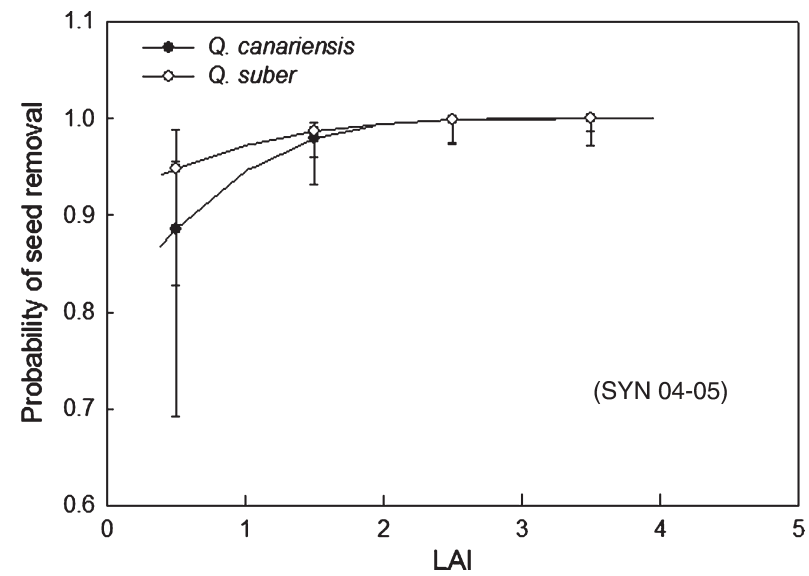

Figure 3. Models resulting in the best fit for acorn removal as function of plant cover (leaf area index, LAI), with 95\% support regions, during SYN 04-05 experiment, where both oak species' seeds with similar weights were experimentally dispersed at the same time.

safe sites might also be crucial for long term viability of oak populations (Díaz 1992, Gómez 2003, Purves et al. 2007). The outcome of plant-scatterhoarder interaction can shift along a continuum from antagonistic (seed predation) to mutualistic (seed dispersal) relations (Bronstein 1994), and this conditional mutualism mostly depends on the relative abundance of seeds versus that of scatterhoarders (Theimer 2004). At low seed/scatterhoarder ratios, rodents act mainly as antagonistic predators, whereas at high values (for example, during mast years) rodents act more as dispersers and less as seed predators (Theimer 2004).

Since the main differences between the two co-occurring species (among several regeneration stages) were observed precisely during the seed-seedling transition (Pérez-Ramos 2007), our modelling approach could help elucidate how overall recruitment of both species varies in the landscape. The ecological implications of inter-specific differences for forest stand dynamics and species coexistence will likely depend on the nature of plant-animal interactions, which are partly determined by food (seed) availability (Jansen et al. 2004), and environmental heterogeneity of the particular site. Accordingly, during a year of low seed production (such as 2004/05 in the study area), most removed acorns are likely consumed later and then $Q$. canariensis could gain an advantage over $Q$. suber and even replace it in certain microhabitats. In contrast, under high seed abundance (such as 2003/04) greater food availability likely satiates seed predators (Janzen 1971, Silvertown 1980, Kelly and Sork 2002), and a larger proportion of removed acorns are cached and probably not relocated later (successful dispersal). In this situation, Q. suber could be favoured over $Q$. canariensis due to the fact that their acorns are clearly preferred by animals (potential dispersers) as a consequence of their bigger size.

It is important to highlight that the differences found between the two oak species were consistent across most of the plant cover gradient, especially during mast years. However, in more closed microhabitats located under several shrub and tree layers, seed removal was very high for both species (probably also predation rates) and, combined with the strong light limitation for emerged seedlings, almost no recruitment will be expected in that type of microhabitat. These results are consistent with previous studies (Pons and Pausas 2007a) but contrast with the documented effect of shrubs as protector of tree seedlings from herbivores under Mediterranean conditions (Gómez 2003, Castro et al. 2004, Pulido and Díaz 2005). On the contrary, the probability of seeds escaping from animal removal was higher in open microhabitats for both oak species, but conditions for seed germination and establishment of seedlings were less suited in this type of microhabitat, due to over-saturation during the wet season (Urbieta et al. unpubl.). Thus, there seems to be a conflict between demographic stages (sensu Schupp 1995); microhabitats with a low removal risk for seeds may exhibit less favourable conditions for subsequent sapling recruitment, and vice versa. Therefore, spatial patterns of seed removal, as a result of the activity and habitat use of seed predators and dispersers, as well as their preferences for acorns of certain species, may have strong influence on tree regeneration and landscape forest dynamics (López-Barrera et al. 2005, Purves et al. 2007). Biotic and abiotic factors may operate synergistically to result in critical sapling recruitment episodes. Understanding how feedbacks between rodent abundance, seed production, disturbances and rainfall variability modulate tree recruitment is critical to developing realistic and mechanistic models of forest dynamics under Mediterranean conditions.

Acknowledgements - We thank the Consejería de Medio Ambiente (Andalusian Government), and Felipe Oliveros, then Director of Los Alcornocales Natural Park, for the facilities and support to carry out our field-work. We also thank Pedro Jordano for his advice in the experimental design, Maite Domínguez and Rocío Sánchez for field assistance, and Eugene W. Schupp for their contributions to an earlier version of the manuscript. This study was supported by FPU and FPI-MEC grants to IMPR and IRU, and by the Spanish MEC projects Heteromed (REN2002-4041C02-02) and Dinamed (CGL2005-5830-C03-01). This research is part of the Globimed ( <www.globimed.net $>$ ) network on forest ecology.

\section{References}

Abrahamson, W. G. and Layne, J. N. 2003. Long-term patterns of acorn production for five oak species in xeric Florida uplands. - Ecology 89: 2476-2492.

Akaike, H. 1992. Information theory and an extension of the maximum likelihood principle. - In: Kotz, S. and Jonson, N. (eds), Breakthroughs in statistics. Springer, pp. 610-624.

Borland International Inc. 1996. Please provide further details.

Bossema, I. 1979. Jays and oaks: an eco-ethological study of a symbiosis. - Behaviour 70: 11-18.

Brewer, S. W. 2001. Predation and dispersal of large and small seeds of a tropical palm. - Oikos 92: 245-255.

Brewer, S. W. and Webb, M. A. H. 2001. Ignorant seed predators and factors affecting the seed survival of a tropical palm. - Oikos 93: 32-41.

Bronstein, J. L. 1994. Conditional outcomes in mutualistic interactions. - Trends Ecol. Evol. 9: 214-217.

Burnham, K. P. and Anderson, D. R. 2002. Model selection and multimodel inference: a practical information-theoretic approach (2nd ed.). - Springer. 
Castro, J. 2006. Short delay in timing of emergence determines establishment success in Pinus sylvestris across microhabitats. - Ann. Bot. 98: 1233-1240.

Castro, J. et al. 2004. Seedling establishment of a boreal tree species (Pinus sylvestris) at its southernmost distribution limit: consequences of being in a marginal Mediterranean habitat. - J. Ecol. 92: 266-277.

Chib, S. and Greenberg, E. 1995. Understanding the MetropolisHasting algorithm. - Am. Stat. 49: 327-335.

Cippolini and Styles 1991. Please provide further details.

Clark, J. S. et al. 1999. Seed dispersal near and far: patterns across temperate and tropical forests. - Ecology 80: 1475-1494.

Crawley 1992. Please provide further details.

Crawley, M. J. and Long, C. R. 1995. Alternate bearing, predator satiation and seedling recruitment in Quercus robur. - J. Ecol. 83: 683-696.

Crow, T. R. 1992. Population dynamics and growth patterns for a cohort of northern red oak (Quercus rubra) seedlings. - Oecologia 91: 191-200.

Curran, L. M. and Leighton, M. 2000. Vertebrate responses to spatiotemporal variation in seed production of mast-fruiting Dipterocarpaceae. - Ecol. Monogr. 70: 101-128.

Delta-T Devices Ltd. 1999. Please provide further details.

Díaz, M. 1992. Rodent seed predation in cereal crop areas of central Spain: effects of physiognomy, food availability and predation risk. - Ecography 15: 77-85.

Edwards, A. W. F. 1992. Johns Hopkins. Likelihood. - University Press, Baltimore, Maryland, USA.

Forget et al. 1998. Please provide further details.

Ganeshaiah and Shaanker 1991. Please provide further details.

Gómez, J. M. 2003. Spatial patterns in long-distance of Quercus ilex acorns by jays in a heterogeneus landscape. - Ecography 26: $573-584$.

Gómez, J. M. 2004. Bigger is not always better: conflicting selective pressures on seed size in Quercus ilex. - Evolution 58: 71-80.

Gómez, J. M. et al. 2003. Impact of vertebrate acorn- and seedling-predators on a Mediterranean Quercus pyrenaica forest. - For. Ecol. Manage. 180: 125-134.

Gómez, J. M. et al. 2008. Effectiveness of rodents as local seed dispersers of Holm oaks. - Oecologia, in press (doi: 10.1007/ s00442-007-0928-3).

Gribko L. S. and Jones W. E. 1995. Test of float method of assessing northern red oak acorn condition. - Tree Planter's Notes 46: 143-147.

Grubb, P. J. 1977. The maintenance of species-richness in plant communities: the importance of the regeneration niche. - Biol. Rev. 52: 107-145.

Harper, J. L. 1977. Population biology of plants. - Academic Press.

Herrera, J. 1995. Acorn predation and seedling production in a low-density population of cork oak (Quercus suber L.). - For. Ecol. Manage. 76: 197-201.

Hilborn, R. and Mangel, M. 1997. The ecological detective: confronting models with data. - Princeton Univ. Press.

Hulme, P. E. and Borelli, T. 1999. Variability in post-dispersal seed predation in deciduous woodland: relative importance of location, seed species, burial and density. - Plant Ecol. 145: 149-156.

Hulme, P. E. and Hunt, M. K. 1999. Rodent post-dispersal seed predation in deciduous woodland: predator response to absolute and relative abundance of prey. - J. Anim. Ecol. 68: 417-428.

Iida, S. 1996. Quantitative analysis of acorn transportation by rodents using magnetic locator. - Vegetatio 124: 39-43.

Ims, R. A. 1990 . On the adaptive value of reproductive synchrony as a predator-swamping strategy. - Am. Nat. 136: 485-498.
Jansen, P. A. et al. 2002. The role of seed size in dispersal by a scatterhoarding rodent. - In: Levey, D. J. et al. (eds), Seed dispersal and frugivory: ecology, evolution and conservation. CAB Int., pp. 209-225.

Jansen, P. A. et al. 2004. Seed mass and mast seeding enhance dispersal by a neotropical scatter-hoarding rodent. - Ecol. Monogr. 74: 569-589.

Janzen, D. H. 1969. Seed eaters versus seed size, number, toxicity and dispersal. - Evolution 23: 1-27.

Janzen 1970. Please provide further details.

Janzen, D. H. 1971. Seed predation by animals. - Annu. Rev. Ecol. Syst. 2: 465-492.

Jensen, T. S. and Nielsen, O. F. 1986. Rodents as seed dispersers in a heath-oak wood succession. - Oecologia 70: 214-221.

Jordano, P. and Schupp, E. W. 2000. Seed disperser effectiveness: the quantity component and patterns of seed rain for Prunus mahaleb. - Ecol. Monogr. 70: 591-615.

Kelly, D. and Sork, V. L. 2002. Mast seeding in perennial plants: why, how, where? - Annu. Rev. Ecol. Syst. 33: 427-447.

Kennedy P. G. 2005. Post-dispersal seed predation varies by habitat not acorn size for Quercus chrysolepis (Fagaceae) and Lithocarpus densiflora (Fagaceae) in central coastal California. - Madroño: 52: 30-34.

Kennedy, P. G. et al. 2004. The importance of seed reserves for seedling performance: an integrated approach using morphological, physiological, and stable isotope techniques. - Oecologia 141: 547-554.

Kikuzawa, K. 1988. Dispersal of Quercus mongolica acorns in a broadleaved decidious forest. 2. Scatterhoarding by mice. - For. Ecol. Manage. 25: 9-16.

Kobe, R. K. 1999. Light gradient partitioning among tropical tree species through differential seedling mortality and growth. - Ecology 80: 187-201.

Koening, W. D. et al. 1994. Acorn production by oaks in central coastal California: variation within and among years. - Ecology 75: 99-109.

Kolb, A. et al. 2007. Environmental context influences the outcome of a plant-seed predator interaction. - Oikos 116: 864-872.

Kollmann, J. and Schill, H. P. 1996. Spatial patterns of dispersal, seed predation and germination during colonization of abandoned grassland by Quercus petraea and Corylus avellana. - Vegetatio 125: 193-205.

López Barrera, F. et al. 2005. Edge effects in a tropical montane forest mosaic: experimental tests of post-dispersal acorn removal. - Ecol. Res. 20: 31-40.

Metropolis et al. 1953. Equation of state calculations by fast computing machines. - J. Chem. Phys. 21: 1087-1092.

Nicotra, A. B. et al. 2002. Seedling root anatomy and morphology: an examination of ecological differentiation with rainfall using phylogenetically independent contrasts. - Oecologia 130: $136-145$.

Ojeda, F. et al. 2000. Plant diversity patterns in the Aljibe Mountains (S. Spain): a comprehensive account. - Biodiv. Conserv. 9: 1323-1343.

Pacala, S. W. et al. 1996. Forest models defined by field measurements: II. Estimation, error analysis and dynamics. - Ecol. Monogr. 66: 1-43.

Pérez-Ramos, I. M. 2007. Factores que condicionan la regeneración natural de especies leñosas en un bosque mediterráneo del sur de la Península Ibérica. PhD thesis. - Univ. of Seville, Spain.

Pérez-Ramos, I. M. and Marañón, T. 2008. Factors affecting postdispersal seed predation in two coexisting oak species: microhabitat, burial and exclusion of large herbivores. - For. Ecol. Manage., in press. 
Pérez-Ramos, I. M. et al. 2007. Acorn removal and dispersal by the dung beetle Thorectes lusitanicus: ecological implications. - Ecol. Entomol. 32: 1-8.

Pérez-Ramos, I. M. et al. 2008. Dynamics of understorey diversity following shrub-clearing of cork oak forests: a five-year study. - For. Ecol. Manage. (doi:10.1016/j.foreco.2008.01.069).

Pons, J. and Pausas, J. G. 2007a. Oak regeneration in heterogeneous landscapes: the case of fragmented Quercus suber forests in the eastern Iberian Peninsula. - For. Ecol. Manage. 231: 196-204.

Pons, J. and Pausas, J. G. 2007b. Rodent acorns selection in a Mediterranean oak landscape. - Ecol. Res. 22, 535-541.

Pons, J. and Pausas, J. G. 2007c. Not only size matters: acorn selection by the European jay (Garrulus glandarius). - Acta Oecol. 31: 353-360.

Purves, D. W. et al. 2007. Environmental heterogeneity, birdmediated directed dispersal, and oak woodland dynamics in Mediterranean Spain. - Ecol. Monogr. 77: 77-97.

Pulido, F. J. and Díaz, M. 2005. Regeneration of a Mediterranean oak: a whole-cycle approach. - Ecoscience 12: 92-102.

Pyke D. A. and Thompson J. N. 1986. Statistical analysis of survival and removal rate experiments. - Ecology 67: 240-245.

Quilchano, C. et al. 2008. Patterns and ecological consequences of abiotic heterogeneity in managed cork oak forests of southern Spain. - Ecol. Res. 23:127-139.

Rey, P. and Alcántara, J. M. 2000. Recruitment dynamics of a fleshy-fruited plant (Olea europaea): connecting patterns of seed dispersal to seedling establishment. - J. Ecol. 88: 622633.

Robbins, C. T. et al. 1987. Role of tannins in defending plants against ruminants: reduction in protein availability. - Ecology 68: 98-107.

Santos, T. and Tellería, J. L. 1997. Vertebrate predation on Holm oak, Quercus ilex, acorns in a fragmented habitat: effects on seedling recruitment. - For. Ecol. Manage. 98: 181-187.

Shimada, T. and Saitoh, T. 2003. Negative effects of acorns on the wood mouse Apodemus speciosus. - Popul. Ecol. 45: 7-17.

Shnurr, J. L. et al. 2002. Direct and indirect effects of masting on rodent populations and tree survival. - Oikos 96: 402-410.

Schupp, E. W. 1995. Seed-seedling conflicts, habitat choice and patterns of plant recruitment. - Am. J. Bot. 82: 399-409.

Silvertown, J. W. 1980. The evolutionary ecology of mast seeding in trees. - Biol. J. Linn. Soc.14: 235-250.

Theimer, T. C. 2003. Intra-specific variation in seed size affects scatterhoarding behaviour of ab Australian tropical rain forest rodent. - J. Trop. Ecol. 17: 177-189.

Theimer, T. C. 2004. Rodent scatterhoarders as conditional mutualists. - In: Forget, P. M. et al. (eds), Seed fate: predation, dispersal and seedling establishment. CPL Press, pp. 283-295.

Urbieta, I. R. et al. 2008. Human and non-human determinants of forest composition in southern Spain: evidence of shifts toward cork oak as a result of management over the past century. - J. Biogeogr., in press.

Valladares, F. and Guzmán, B. 2006. Canopy structure and spatial heterogeneity of understory light in an abandoned Holm oak woodland. - Ann. For. Sci. 63: 1-13.

Verdú, M. and Traveset, A. 2005. Early emergence enhances plant fitness: a phylogenetically controlled meta-analysis. - Ecology 86: $1385-94$.

Verdú, J. R. et al. 2007. Acorn preference by the dung beetle Thorectes lusitanicus under laboratory and field conditions. - Anim. Behav. 74: 1697-1704.
Wolf, J. O. 1996. Population fluctuations of mast-eating rodents are correlated with production of acorns. - J. Mammal. 77: $850-856$.

Xiao, Z. et al. 2004. Dispersal and germination of big and small nuts of Quercus serrata in a subtropical broad-leaved evergreen forest. - For. Ecol. Manage. 195: 141-150.

Xiao et al. 2006. Please provide further details.

Zavala, M. A. and Zea, G. E. 2004. Mechanisms maintaining biodiversity in Mediterranean pine-oak forests: insights from a spatial simulation model. - Plant Ecol. 171: 197-207.

Zavala, M. A. et al. 2000. Constraints and tradeoffs in Mediterranean plant communities: the case of holm oak (Quercus ilex L.)-Aleppo pine (Pinus halepensis Mill.). - Bot. Rev. 66: 119-149.

\section{Appendix 1}

\section{Binomial vs failure time analysis}

From a statistical point of view, this study could be used as an interesting example of the comparison between two common types of analyses applied in seed removal studies. Most studies only consider the final seed removal rate, treating the dependent variable as a binomial, i.e. with each independent trial resulting in just two possible final outcomes: a seed manipulated by animals or unaffected. However, the inclusion of survival times can provide more relevant information, as documented in the present case study. Failure time analyses allowed us to detect the effect of LAI and seed size, which remained masked by using the binomial approach (Fig. A1). This was especially noticeable in those situations where the overall seed removal was very high, such as in DI 04-05, when resource availability was scarce and likely seed consumers density very high. However, seed survival times statistically differed as function of seed size and depending on where seeds were dispersed (plant cover). This could have important implications if we treat species recruitment as a dynamic process, in which the time elapsing from seed dispersal until the seed is removed by animals can affect its capacity to establish as a seedling (see Introduction section for the importance of time to removal, and Data analyses section for statistical details of both methods).

\section{Appendix 2}

Functional responses fitted in the models calibrated for this study were the following:

[i] Linear: A+SFactor ${ }_{i}$; [ii] Exponential: $\mathrm{Ae}^{\text {(sFactor) }}$; [iii] Power: A*Factor ${ }_{i}$

[iv] Logistic: where A and $S$ are parameter estimates that maximized the likelihood function, and Factor ${ }_{i}$ are the measured predictor variables for each acorn 'i'. 
Binomial

(a)

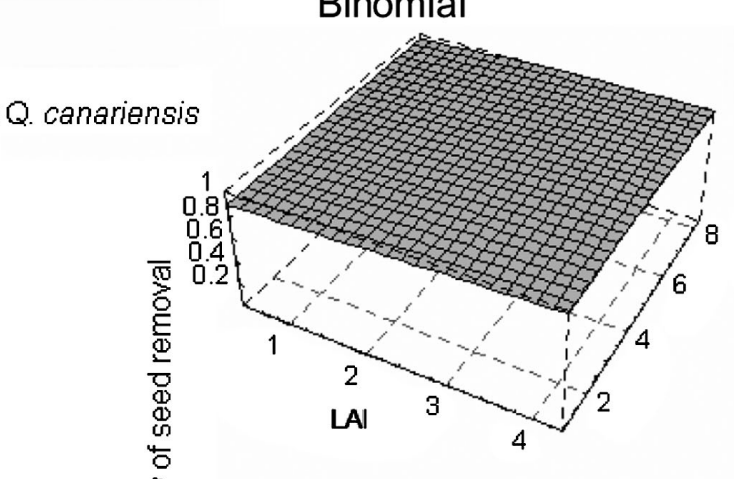

(b) Q. suber

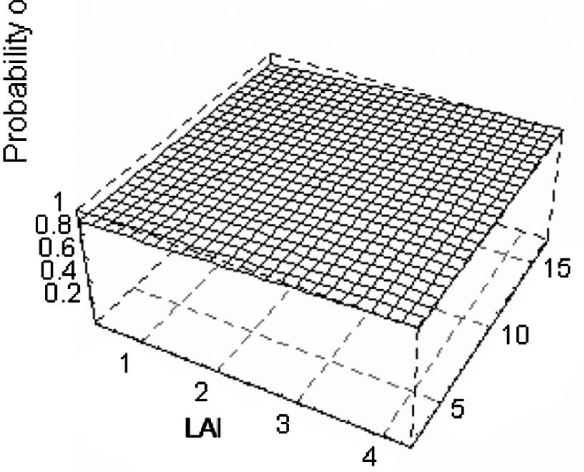

Failure Time
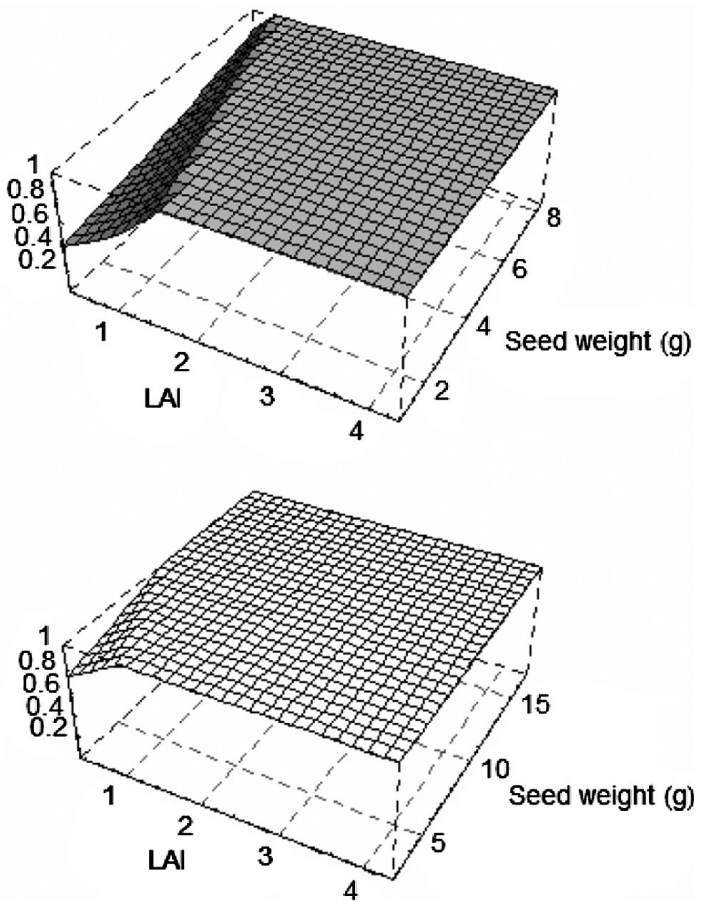

Figure A1. Models resulting in the best fit for seed removal of both species, Q. canariensis (a) and Q. suber (b), during DI 04-05. Notice different scales in the axes. Binomial and failure time approaches are compared. No effect of seed size nor LAI were captured when assuming a simple binomial, whereas introducing "survival times" we observed that in open areas (low LAI) seeds "survived" longer without being manipulated by seed predators or dispersers (especially smaller ones), with important ecological consequences for tree recruitment. 